examinations, and 176,832 were counselling sessions. Out of total number of preventive examinations, there were 281,029 check-up examinations (85.8\%), of which 166,240 in infants (4.4 per infant) and 114,789 in preschool children $(0.5$ examinations per child). During preventive visits, a total of 107,483 referrals were issued (17.6\% of all issued referrals), of which $57.3 \%$ for infants. Most referrals from preventive visits of infants were for diagnostic purposes (40.1\%), and from preventive visits of preschool children for the examination by consultant physician (52.2\%).

Conclusion According to CEZIH data, preventive activities account for a fifth of the total activities in children's health care on a primary level. The plan and program of health care measures sets four check-up examinations in infants, which, according to CEZIH data, has been achieved. However, in the period after the first year of life, three systematic examinations per preschool child were not performed or data on this were not recorded in the CEZIH. On average, every fifth preventive visit results in the discovery of a pathological condition due to which the infant or young child is referred for further treatment. Monitoring the growth and development of children by conducting regular check-up examinations is an important measure in the prevention and early detection of developmental disorders and the preservation of children's health.

\section{CASE REPORT: THE MULTIDISCIPLINARY TREATMENT OF SOMATIC SYMPTOM DISORDER IN A SCHOOL-AGED BOY}

Ivan Begovac*, Lena Santrić, Silvana Pleština, Veronika Nives Zorić, Irena Bambulović. Department for psychiatry and psychological medicine, School of Medicine, University of Zagreb, Clinical hospital center Zagreb

\subsection{6/archdischild-2021-europaediatrics.21}

Somatic Symptom Disorder (SSD), formally known as somatoform disorder, can be found in the Diagnostic and Statistical Manual of Mental Disorders (DSM-5) in the category titled: Somatic Symptom and Related Disorders. In the 10th revision of the International Classification of Diseases (ICD-10), somatoform disorder can be found under the code F45, with the more specific F45.4 being: persistent somatoform pain disorder. A multidisciplinary approach is often used in the treatment of this disorder. Medical professionals involved in the team include: pediatricians, child and adolescent psychiatrists, psychotherapists, psychologists, nurses, and other collaborating professionals. In this case report we present the case of a boy who had an unfavorable course of illness with recurring abdominal pain, loss of functionality, and inability to attend school for months. The patient was treated multiple times, both as an inpatient and outpatient, by pediatricians, child and adolescent psychiatrists, as well as the other members of the multidisciplinary team. Unfavorable prognostic factors in this case were: resistance and recurrence of symptoms, tension, and high emotional sensitivity. On the other hand, favorable prognostic factors were: motivation for treatment and an appropriate level of development of mental structure. During the patient's last treatment in the hospital on the Department of Child and Adolescent psychiatry, an improvement in symptoms was achieved with a reduction of pain, as well as the reestablishment of school attendance at the hospital. In a number of cases, SSD has a chronic course, which poses a great challenge for treatment in practice today.

\section{BENEFITS OF TRAINED DOGS FOR MENTAL AND PHYSICAL HEALTH ACCORDING TO THE HOLISTIC APPROACH (AAI, AAT)}

Romana Misir* , Adrijana Hnojčik, Renata Fridrih, Anica Persoglia Petrac. Centar za socijalnu skrb Bjelovar, Podružnica Obiteljski centar

\subsection{6/archdischild-2021-europaediatrics.22}

Over the last 30 years, there has been a rise in interventions and therapies with the help of animals (AAI, AAT). Within each of the mentioned procedures, there is an emphasis on the potential benefits of active use of dogs with both children and adults. In Croatia, there has also been a rise in various associations which do their activities with the help of animals, especially dogs. Since 2012, the Our Children Society of Sisak (Društvo Naša djeca Sisak), through the partnership with healthcare, educational and social care instititutions along with judiciary preparations is actively implementing an innovative project of direct work with trained dogs and guides according to the holistic approach (AAI, AAT) within activities with the vulnerable user groups. The neccessity of a multidisciplinary approach for the benefit of users and patients has achieved an unbreakable synergy between man and dog. Generally speaking, there are not that many healthcare institutions associated with the project using therapy dogs. For example, the pediatric clinic, and the Polyclinic for the protection of children and the young in Zagreb (Poliklinika za zaštitu djece i mladih Grada Zagreb), the Family Center Bjelovar (Obiteljski centar Bjelovar) are one of the first institutions that use trained guides and dogs according to this method, and every user and patient is happy with it. Incorporating therapy dogs in working with children results in an interaction between the child and the trained dog, guided by a trained dog expert, with the goal of improving psychophysical abilities. The activities are devised and directed towards the specific needs and difficulties depending on the individual (these can be language, emotional, and motor system difficulties). The guide dog expert is responsible for ensuring optimal conditions and a pleasant environment which are, in turn, to benefit the child so it can be able to use all of the advantages of animal-assisted therapy within the therapy process. The innovative method and research results suggest that active incorporation of trained dogs in therapies and interventions with children according to the holistic approach makes reaching certain therapy goals much more easy, and it also benefits the child in terms of developing contact and trust between the child and the experts more easily. Also, it gives the child a sense of security in the therapy setting, makes communicating unwanted emotions much easier, and it also increases confidence and empathy in children. In addition to this, it also reduces stress, anxiety and feelings of lonelyness and reduces the sensation of physical pain. Most of these effects can be explained throught the influence of the hormone oxytocin whose levels rise while petting or talking with the dogs, and since it also has an antistress effect it also reduces the stress levels in people. The poster will show the perspective of everyday work of guide dog experts with children, and, in more detail, it will present the work of dogs trained according to the holistic approach (AAI, AAT) with the goal of protecting the mental and 